\title{
Discovery of potent necroptosis inhibitors targeting RIPK1 kinase activity for the treatment of inflammatory disorder and cancer metastasis
}

\author{
Jue Hou ${ }^{1,2}$, Jie Ju, ${ }^{1,2}$, Zili Zhang ${ }^{1,2}$, Cong Zhao ${ }^{1,2}$, Zhanhui Li ${ }^{3}$, Jiyue Zheng ${ }^{3}$, Tian Sheng ${ }^{3}$, Hongjian Zhang ${ }^{3}$, Linkun Hu ${ }^{4}$, \\ Xiaoliang $\mathrm{Yu}^{1,2,5,6}$, Wei Zhang ${ }^{1,2,5,6}$, Yangxin $\mathrm{Li}^{7}$, Meng $\mathrm{Wu}^{1,2}$, Haikuo Ma ${ }^{1,3}$, Xiaohu Zhang ${ }^{3}$ and Sudan $\mathrm{He}^{1,2,5,6}$
}

\begin{abstract}
Necroptosis is a form of regulated necrosis controlled by receptor-interacting kinase 1 (RIPK1 or RIP1), RIPK3 (RIP3), and pseudokinase mixed lineage kinase domain-like protein (MLKL). Increasing evidence suggests that necroptosis is closely associated with pathologies including inflammatory diseases, neurodegenerative diseases, and cancer metastasis. Herein, we discovered the small-molecule PK6 and its derivatives as a novel class of necroptosis inhibitors that directly block the kinase activity of RIPK1. Optimization of PK6 led to PK68, which has improved efficacy for the inhibition of RIPK1-dependent necroptosis, with an $\mathrm{EC}_{50}$ of around 14-22 nM in human and mouse cells. PK68 efficiently blocks cellular activation of RIPK1, RIPK3, and MLKL upon necroptosis stimuli. PK68 displays reasonable selectivity for inhibition of RIPK1 kinase activity and favorable pharmacokinetic properties. Importantly, PK68 provides strong protection against TNF-a-induced systemic inflammatory response syndrome in vivo. Moreover, pre-treatment of PK68 significantly represses metastasis of both melanoma cells and lung carcinoma cells in mice. Together, our study demonstrates that PK68 is a potent and selective inhibitor of RIPK1 and also highlights its great potential for use in the treatment of inflammatory disorders and cancer metastasis.
\end{abstract}

\section{Introduction}

Necroptosis is a form of regulated necrosis that is tightly controlled by the activation of receptor-interacting protein kinases (RIPKs) ${ }^{1}$. In response to initiating necroptotic signals from death receptors, Toll-like receptor or interferon receptors, RIPK1 (RIP1) and RIPK3 (RIP3), form a protein complex through their RIP homotypic interaction

Correspondence: Haikuo Ma (mahaikuo123@163.com) or Xiaohu Zhang (xiaohuzhang@suda.edu.cn) or Sudan He (hesudan2018@163.com)

${ }^{1}$ Cyrus Tang Hematology Center and Collaborative Innovation Center of Hematology, State Key Laboratory of Radiation Medicine and Protection, Soochow University, 215123 Suzhou, Jiangsu, China

${ }^{2}$ Key Laboratory of Stem Cells and Biomedical Materials of Jiangsu Province and Chinese Ministry of Science and Technology, Soochow University, 215123 Suzhou, Jiangsu, China

Full list of author information is available at the end of the article.

These authors contributed equally: Jue Hou, Jie Ju, Zili Zhang

Edited by U. Maurer motif (RHIM) domains, leading to activation of both proteins necroptosis ${ }^{2-5}$. The kinase activities of RIPK1 and RIPK3 are essential for their function in necroptosis. Activated RIPK3 phosphorylates its substrate MLKL ${ }^{6,7}$, which further oligomerizes and translocates to the plasma membrane for necroptosis execution ${ }^{8-10}$. Necroptosis results in cell membrane rupture and the release of cellular contents including damage-associated molecular molecules (DAMPs), thus leading to the induction of inflammation. Necroptosis is emerging as an important form of cell death involved in a wide variety of inflammatory or degenerative disorders including tumor necrosis factor (TNF)-induced systemic inflammatory response syndrome $(\mathrm{SIRS})^{11,12}$, systemic inflammatory responses in $\mathrm{A}^{2} 0^{-1-}$ mice ${ }^{13,14}$, chronic proliferative dermatitis (cpdm) in SHARPIN $^{-1-}$ mice $^{12}$, colitis $^{15}$,

\section{(c) The Author(s) 2019}

(c) (i) Open Access This article is licensed under a Creative Commons Attribution 4.0 International License, which permits use, sharing, adaptation, distribution and reproduction cc) in any medium or format, as long as you give appropriate credit to the original author(s) and the source, provide a link to the Creative Commons license, and indicate if changes were made. The images or other third party material in this article are included in the article's Creative Commons license, unless indicated otherwise in a credit line to the material. If material is not included in the article's Creative Commons license and your intended use is not permitted by statutory regulation or exceeds the permitted use, you will need to obtain permission directly from the copyright holder. To view a copy of this license, visit http://creativecommons.org/licenses/by/4.0/. 
neurodegenerative diseases ${ }^{16}$ and ischemia-reperfusioninduced injury in the brain ${ }^{17}$, kidney ${ }^{18,19}$, and heart ${ }^{20,21 .}$ In addition, the necroptosis of endothelial cells has been reported to promote tumor metastasis by facilitating extravasation of circulating tumor cells from the blood system $^{22}$. Therefore, interventions targeting the necroptosis signaling pathway could potentially be used for the treatment the aforementioned necroptosis-associated diseases.

RIPK1 is a multifunctional protein involved in the regulation of cell death and pro-survival nuclear factor- $\mathrm{k} B$ (NF-KB) signaling. RIPK1 contains an N-terminal serine/ threonine kinase domain, a C-terminal death domain (DD), and an intermediate domain (ID) that contains an RHIM domain. The kinase activity of RIPK1 is essential for its role in mediating necroptosis, whereas this activity is dispensable for RIPK1's function in NF- $\mathrm{BB}$ activation $^{5,23}$. Extensive studies have shown that inhibition of RIPK1 kinase activity by the chemical compound necrostatin-1 or by knock-in of a kinase-dead form of RIPK1 can ameliorate necroptosis-associated pathologies in mouse models of various diseases, including inflammatory diseases (e.g. colitis and dermatitis) and in neurodegenerative diseases (e.g. multiple sclerosis (MS) and amyotrophic lateral sclerosis (ALS) $)^{24,25}$. Therefore, the suppression of the RIPK1 kinase activity could be a promising therapeutic approach for the treatment of these diseases. Recently, it has been shown that suppression of RIPK1 kinase activity improves anti-tumor immunity by modulating tumor-associated macrophages ${ }^{26}$; this occurs independently of RIPK3-mediated necroptosis, demonstrating that the kinase activity of RIPK1 can be viewed as a new immunomodulatory target for the development of new anti-cancer therapies.

The kinase domain of RIPK1 is thus an attractive target for intervention with specific chemical inhibitors. Necrostatin-1 (Nec-1) was identified as the first necroptosis inhibitor; it directly blocks RIPK1 kinase activity ${ }^{17,27}$. $\mathrm{Nec}-1$ and its improved analog Nec-1s (7-Cl-O-Nec-1) were found to interact with RIPK1 at the back pocket of the ATP-binding site and to exhibit remarkable kinome selectivity $^{28-30}$. However, these compounds displayed moderate potency, suboptimal pharmacokinetic profiles, and had off-target activities (e.g. indoleamine-2,3-dioxygenase). The RIPK1 inhibitors developed by GSK such as GSK963 and GSK2982772 have been shown to be extremely potent in human cells, but they have highly reduced cellular efficacy in mouse and rat $^{31,32}$. This species selectivity imposes limitations on explorations of their in vivo therapeutic value with mouse or rat disease models. Therefore, identifying novel RIPK1 inhibitors with high efficacy and conserved potency among human, mouse, and rat would greatly facilitate the development of new therapeutic approaches. In the present study, we discovered PK68 as a novel inhibitor of RIPK1 kinase activity that displays potent cellular efficacy and that suppresses necroptosis in human, mouse, and rat cells. In addition, PK68 displays favorable kinome selectivity and pharmacokinetic properties. Notably, pre-treatment of PK68 powerfully blocks TNF-induced lethal shock and inflammatory responses as well as tumor metastasis in vivo. These findings suggest that PK68 can be used in the development of new therapies for the treatment of necroptosis-activated pathologies including inflammatory disorders and cancer metastasis.

\section{Results}

PK6 efficiently blocks TNF-a induced necroptosis in both human and mouse cells

Necroptosis is tightly regulated by RIP kinases including RIPK1 and RIPK3. To develop new necroptosis inhibitors, we screened a small-molecule library of around 240 potential kinase inhibitors that were designed with novel structures to affect the ATP-binding pocket of protein kinases. Human colon cancer HT-29 cells were treated with these compounds for $2 \mathrm{~h}$, followed by treatment with necroptotic stimuli (TNF $\alpha$, Smac mimetic, and z-VAD) that are known to activate TNF-mediated necroptosis ${ }^{2}$. After $48 \mathrm{~h}$, cell viability was analyzed by monitoring ATP levels. This screen identified PK6 as an effective inhibitor of TNF-induced necroptosis with an $\mathrm{EC}_{50}$ of $\sim 1.2 \mu \mathrm{M}$ (Fig. 1a-c). Consistently, PK6 blocked TNF-induced necroptosis in human leukemia U937 cells with an $\mathrm{EC}_{50}$ of $\sim 1.33 \mu \mathrm{M}$ (Fig. 1d). Further, we evaluated the effect of PK6 on TNF-induced necroptosis in mouse cells and found that PK6 efficiently inhibited TNF-induced necroptosis in both mouse embryonic fibroblasts (MEFs) with $\mathrm{EC}_{50}$ of $\sim 0.95 \mu \mathrm{M}$ and mouse fibroblast L929 cells with $\mathrm{EC}_{50}$ of $\sim 0.76 \mu \mathrm{M}$ (Fig. 1e, f). Taken together, these results demonstrate that PK6 is an inhibitor of TNFinduced necroptosis in both human and mouse cells.

\section{Chemical optimization of PK6 leads to improvements in anti-necroptotic activity}

Having established that PK6 is a novel inhibitor of TNFinduced necroptosis in both human and mouse cells, we next explored strategies to enhance the anti-necroptotic efficacy and drug-like properties of PK6. As a screening hit, PK6 exhibited numerous undesirable characteristics, for example the 2-chlorine atom on the center pyridine ring might act as an active leaving group, thereby potentially eliciting toxicity in biological systems (Fig. 2d, marked in red). Furthermore, the solubility of PK6 was poor, most likely due to the number of $\mathrm{sp} 2$ carbons present in PK6.

In order to address these problems, we used a bioisosteric strategy ${ }^{33}$ to substitute the potentially toxic chlorine with a methyl group ${ }^{34}$; we also introduced sp3 carbons on 
a

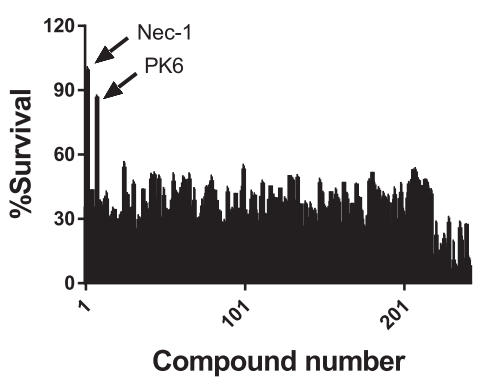

b PK6

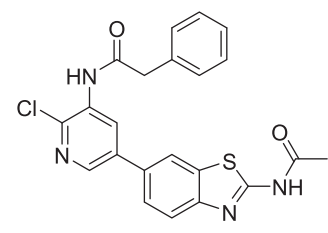

c

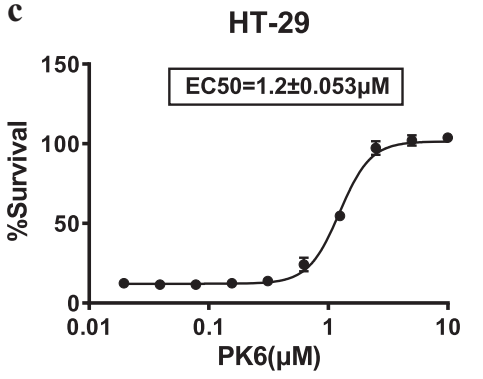

d

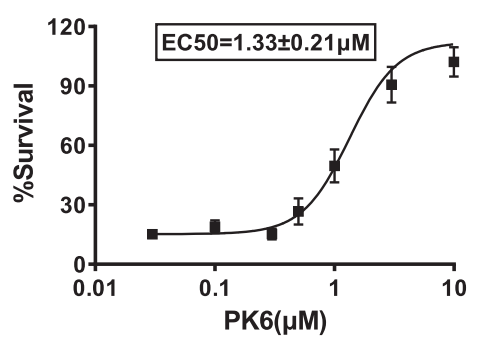

e

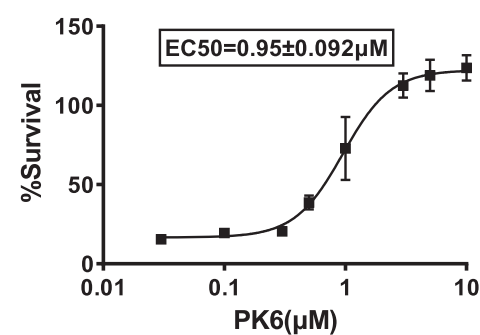

f

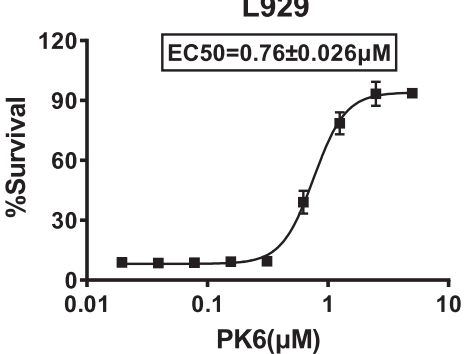

Fig. 1 PK6 efficiently blocks TNF-a induced necroptosis in both human and mouse cells. a HT-29 cells cultured in 96-well plates were pretreated with the indicated compounds $(10 \mu \mathrm{M})$ from a library consisting of $\sim 240$ compounds that we designed with novel structures for $1 \mathrm{~h}$ and subsequently treated with $40 \mathrm{ng} / \mathrm{ml}$ TNF-a (T), $100 \mathrm{nM}$ Smac mimetic (S), and the caspase inhibitor $20 \mu \mathrm{M} \mathrm{z-VAD(Z)} \mathrm{for} 48$ h. Cell viability was assessed by measuring ATP levels. Data are represented as the mean \pm standard deviation of duplicates. $\mathbf{b}$ Chemical structure of PK6. c Dose response curve and $\mathrm{EC}_{50} \pm \mathrm{SD}$ value for PK6 in TNF-a induced necroptosis in HT-29 cells. Cells were pretreated with indicated concentrations of PK6 for $1 \mathrm{~h}$ prior to the treatment with $T(40 \mathrm{ng} / \mathrm{ml}), \mathrm{S}(100 \mathrm{nM})$, and Z $(20 \mu \mathrm{M})$ for $48 \mathrm{~h}$. Cell viability was assessed by measuring ATP levels. $\mathbf{d}$ U937 cells were pretreated with indicated concentrations of PK6 for $1 \mathrm{~h}$ followed by the treatment with $\mathrm{T}(40 \mathrm{ng} / \mathrm{ml}), \mathrm{S}(100 \mathrm{nM})$, and Z $(20 \mu \mathrm{M})$ for $24 \mathrm{~h}$. e MEF cells were pretreated with indicated concentrations of PK6 for $1 \mathrm{~h}$ followed by the treatment with T ( $40 \mathrm{ng} / \mathrm{ml}), \mathrm{S}(100 \mathrm{nM})$, and Z (20 $\mu \mathrm{M})$ for $24 \mathrm{~h}$. f L929 cells were pretreated with indicated concentrations of PK6 for $1 \mathrm{~h}$ prior to the treatment with S $(100 \mathrm{nM})$ and Z $(20 \mu \mathrm{M})$ for $24 \mathrm{~h}$. Data are represented as the mean \pm standard deviation of triplicates

ring $\mathrm{C}$ (Fig. 2d, marked in pink) ${ }^{35}$. The results were very encouraging: PK67 displayed significant improvement in inhibiting TNF-induced necroptosis in both human and mouse cells (250 and $130 \mathrm{nM}$, respectively; Fig. 2a-c). Further modifications were made on the center ring $\mathrm{A}$ and the bicyclic ring $\mathrm{B}$, and an oxygen atom was introduced at the top region of the scaffold (Fig. 2d, marked in green). These modifications proved to be successful: numerous compounds with improved potency were thusly obtained (e.g., PK81, 84, 86, 93; Fig. 2a-c). These efforts ultimately culminated in the identification of PK68, a highly potent inhibitor of TNF-induced necroptosis (23 and $13 \mathrm{nM}$ in human and mouse cells, respectively; Fig. 2a-c). PK68 exhibits significant improvement in antinecroptotic activity and in its physicochemical properties as compared with the screening hit PK6 (Supplementary Table 1). The structural evolution underlying the development of PK68 is summarized in Fig. 2d. The synthetic experimental details and characterization of compounds can be found in supplementary information (Supplementary Figs. 1-18 and Synthetic Procedures).
PK6 and PK68 block cellular activation of RIPK1, RIPK3, and MLKL upon necroptotic stimuli

In addition to TNF-induced necroptosis, it is known that TLR3 or TLR4 activation can also trigger necropto$\mathrm{sis}^{36}$. We further evaluated the effects of PK6 and PK68 on TLR3- and TLR4-mediated necroptosis induced by poly(I: C)/z-VAD and LPS/z-VAD, respectively. Treatment of PK6 or PK68 significantly blocked both TLR3- and TLR4mediated necroptosis in mouse bone marrow-derived macrophages (Fig. 3a). Consistently, in rat bone marrowderived macrophages, PK6 and PK68 showed inhibitory effects on both TNFR- and TLR-mediated necroptosis (Fig. 3b). These results support that PK6 and PK68 have a common mechanism of inhibiting the conserved necroptosis signaling pathways among mouse, rat, and humans. To investigate the molecular mechanism of PK series-mediated necroptosis inhibition, we examined the effects of these compounds on the major steps of necroptotic signaling, including activation of RIPK1, RIPK3, and MLKL. RIPK1, RIPK3, and MLKL were phosphorylated upon necroptotic stimuli, while addition 


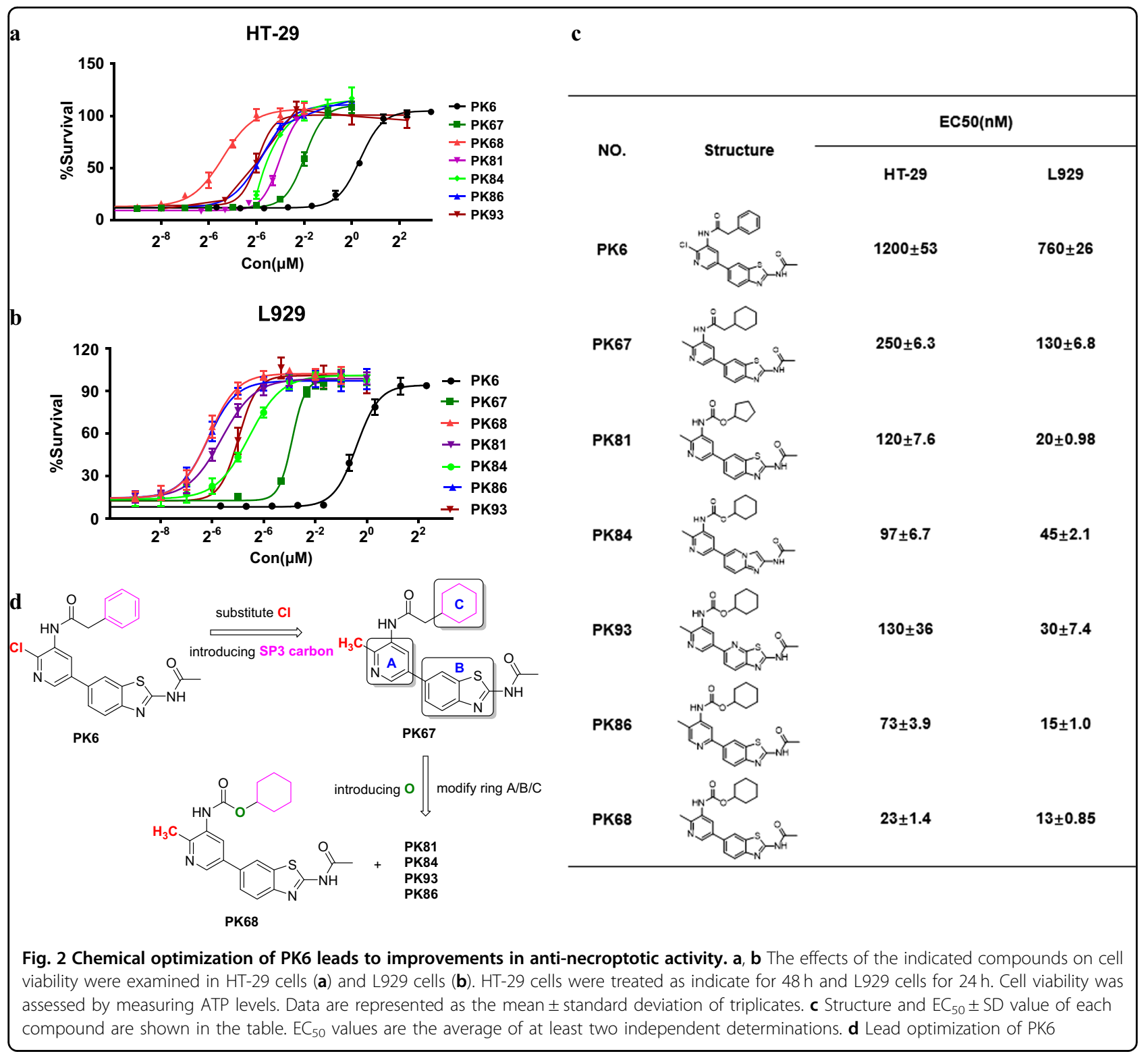

of PK6 or PK68 completely abolished phosphorylation of RIPK1, RIPK3, and MLKL (Fig. 3c). It has been shown previously that RIPK3 activation leads to the formation of RIPK3 puncta during necroptosis. We observed that treatment of PK6 or PK68 prevented generation of RIPK3 puncta (Fig. 3d), suggesting that PK6 and PK68 block necroptosis through the suppression of RIPK3 function or signaling upstream of RIPK3 activation.

PK68 is a highly selective inhibitor of RIPK1 kinase activity Having shown that PK6 and PK68 can inhibit activation of both RIPK1 and RIPK3 during TNF-mediated necroptosis, we sought to determine if PK6 and PK68 can directly target RIPK1 or and RIPK3 by performing in vitro kinase assays. Both PK6 and PK68 were able to block the kinase activities of both human RIPK1 and mouse RIPK1 in vitro (Fig. 4a and Supplementary Fig. 19). Compared to PK6, PK68 showed improved activity for inhibiting RIPK1 kinase activity, with an $\mathrm{IC}_{50}$ of around $90 \mathrm{nM}$, a value consistent with its cellular activity against necroptosis. In contrast, neither PK6 nor PK68 affected RIPK3 kinase activity, even at a $1000 \mathrm{nM}$ concentration (Fig. 4b).

Further, we evaluated the selectivity of PK68 against a panel of 369 kinases provided by Reaction Biology (at $1000 \mathrm{nM})$. PK68 was found to be a reasonably selective RIPK1 inhibitor, displaying $>50 \%$ inhibition of five kinases (TRKA, TRKB, TRKC, TNIK, and LIMK2) among all of the other tested kinases (Fig. 4c and Supplementary Table 2). In addition, we followed on some of the active "hits" from the kinome scan. PK68 was tested against TNIK and 
$\mathbf{a}$

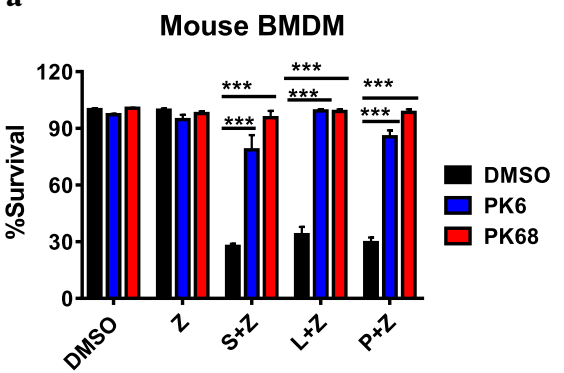

c

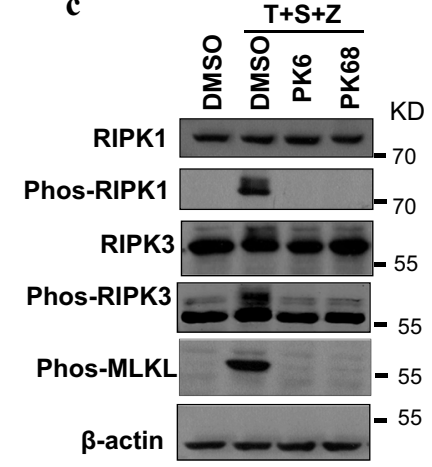

d b
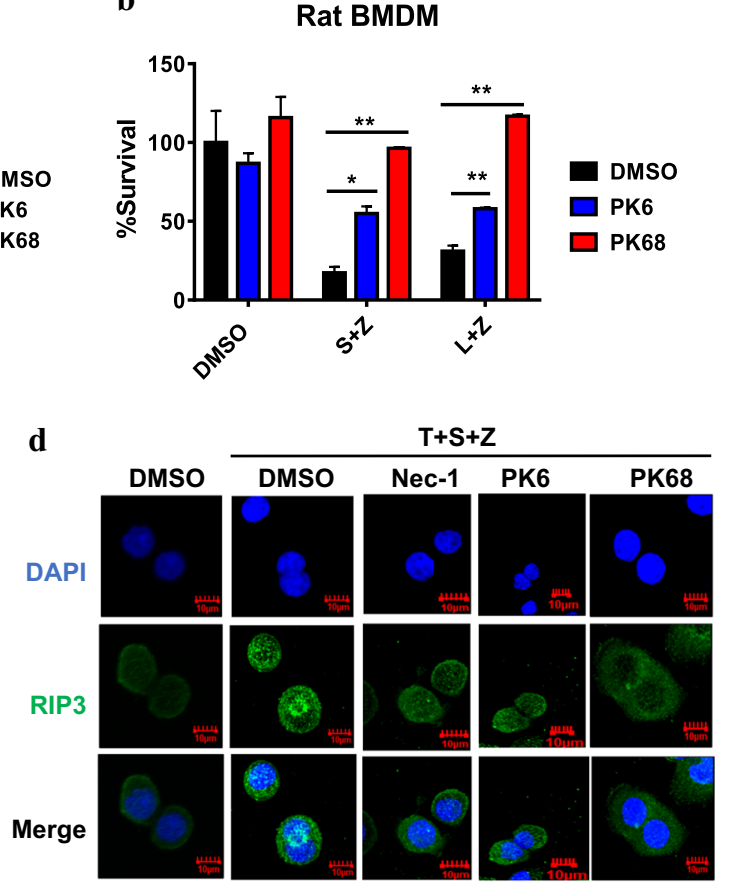

Fig. 3 PK6 and PK68 block cellular activation of RIPK1, RIPK3, and MLKL upon necroptotic stimuli. a, b Bone marrow-derived macrophages from C57BL/6 mice or rat were pretreated with DMSO, PK6 $(10 \mu \mathrm{M})$, or PK68 $(100 \mathrm{nM})$ for $1 \mathrm{~h}$ and subsequently treated with indicated stimuli for 24-30 h. Cell viability was determined by measuring ATP levels. L, LPS (20 ng/ml); P, poly(l:C) $(50 \mu \mathrm{g} / \mathrm{ml}) ; \mathrm{S}(100 \mathrm{nM}) ; Z(10 \mu \mathrm{M})$. Data are represented as the mean \pm standard deviation of triplicates. $\mathbf{c H T}-29$ cells were treated with the indicated compound for $1 \mathrm{~h}$ prior to the treatment of T (40 ng/ml), S $(100 \mathrm{nM})$, and Z $(20 \mu \mathrm{M})$ for additional $8 \mathrm{~h}$. Cell lysates were harvested and subjected to western blot analysis for phosphorylation of RIPK1, RIPK3, and MLKL. $\mathbf{d}$ The effects of PK6 and PK68 on the formation of RIPK3 puncta. HT-29 cells stably expressing Flag-tagged RIPK3 were pretreated with indicated compounds for $1 \mathrm{~h}$ prior to the treatment of $\mathrm{T}(100 \mathrm{ng} / \mathrm{ml}), \mathrm{S}(100 \mathrm{nM})$, and Z $(20 \mu \mathrm{M})$ for additional $12 \mathrm{~h}$. The distribution of RIPK3 was detected by immunofluorescence. ${ }^{*} P<0.05 .{ }^{* *} P<0.01$. ${ }^{* *} P<0.001$

TRKA by a reputable CRO company. PK68 was found to be not very active against these two kinases, with $\mathrm{IC}_{50}$ $\sim 10,000 \mathrm{nM}$ (Supplementary Fig. 20). RIPK1 is known to mediate NF- $\mathrm{kB}$ activation independently of its kinase activity $^{23}$. Consistently, PK6 and its derivatives including PK68 showed no impact on TNF-induced NF- $\mathrm{kB}$ activation (Supplementary Fig. 21). It has been shown that homodimerization of RIPK3 or MLKL induced by the dimerizer leads to necroptosis bypassing the upstream signals ${ }^{10,37}$. We conducted experiments in which NIH3T3 cells stably expressing mouse RIPK3 fused to FK506binding protein (FKBP) carrying the F36V mutant were treated with the dimerizer AP20187 to enforce dimerization of RIPK3, and found that this successfully led to the activation of RIPK3 and necroptosis (Fig. 4d). This dimerized RIPK3-induced necroptosis was blocked by RIPK3 inhibitor GSK873 but was not blocked by the RIPK1 inhibitor necrostatin-1. Moreover, neither PK6 nor PK68 blocked RIPK3 dimerization-induced necroptosis (Fig. 4d), suggesting that both PK6 and PK68 do not affect RIPK3 or its downstream events. HeLa expressing MLKL (1-190aa) fused to DmrB, which is identical to FKBP
F36V mutant, treated with AP20187 resulted in MLKL polymerization, which has been reported to activate MLKL and necroptosis independently of RIPK1 and RIPK $3^{38}$ (Fig. 4e). Consistently, neither PK6 nor PK68 had any effect on this polymerized MLKL-induced form of necroptosis, which was however effectively suppressed by MLKL inhibitor necrosulfonamide (NSA) (Fig. 4e). Collectively, these results demonstrate that PK68 is a potent and selective inhibitor of necroptosis that acts by suppressing RIPK1 kinase activity.

\section{A docking study indicates that PK68 is a type II inhibitor of RIP1 kinase}

To analyze the interaction patterns between PK68 and RIPK1 kinase, we docked PK68 into the binding pocket of the RIPK1 crystal structure (PDB ID: 4NEU ${ }^{39}$ ) using the extra precision (XP) scoring function in Glide docking ${ }^{40}$. Note that detailed descriptions of binding site generation and the Glide docking pipeline have been described in our previous study ${ }^{41}$. The chemical structures of PK68 and compound 8 from 4 NEU are shown in Fig. 5a. The predicted binding conformation of PK68 and the interaction 


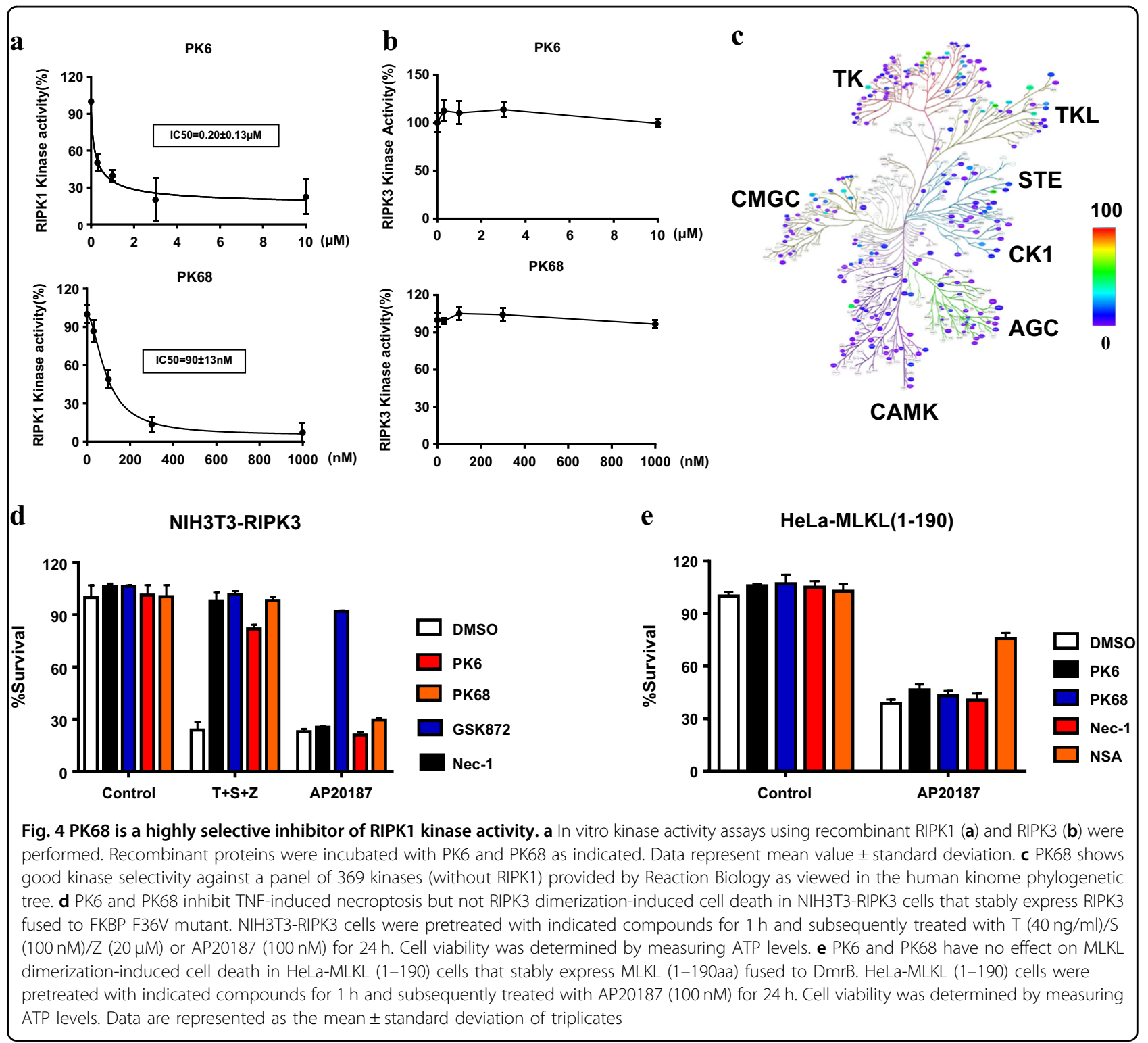

patterns between PK68 and RIPK1 kinase domain are shown in Fig. 5b and c, respectively.

Similar to the co-crystallized ligand of the 4NEU crystal complex, PK68 was predicted as a typical type II kinase inhibitor; it interacted with a DLG (Asp156-Leu157-Gly158)-out form of the RIPK1 protein (Fig. 5b). The N-acetamide of PK68 is apparently a hinge binder, forming hydrogen bond interaction with the backbone $\mathrm{CO}$ of residue Met95. The benzo[d]thiazole in the tail group ( $N$-(benzo[d]thiazol-2-yl)acetamide) of PK68 can interact with residue Ile43 (arene-H interaction) (Fig. 5c). In addition, the carbonyl oxygen of carbamic acid in the head group of PK68 can form a hydrogen bond with the backbone amide of residue Asp156 in the DLG motif. Moreover, the cyclohexane group of PK68 is buried deeply in the hydrophobic allosteric pocket that encompasses residues Met66, Met67, Leu70, Val75, Leu129, Val134, and Leu159 $9^{39}$ created by the DLG-out conformation in RIPK1 (Fig. 5b, c).

PK68 exhibits a favorable pharmacokinetic profile and no obvious toxicity in mice

Encouraged by our overall satisfactory in vitro potency and selectivity data for PK68, we decided to assess its in vivo pharmacokinetic profile. When dosed orally in ICR mice, PK68 was quickly absorbed into the bloodstream with a Tmax of $0.5 \mathrm{~h}$ and a Cmax of $2423 \mathrm{ng} / \mathrm{ml}$. PK68 displayed a moderate clearance $(21 \mathrm{ml} / \mathrm{min} / \mathrm{kg})$, a good steady-state volume of $1.0 \mathrm{~L} / \mathrm{kg}$, and a half-life of $1.3 \mathrm{~h}$. The oral exposure of PK68 was good, with an AUC of 
a
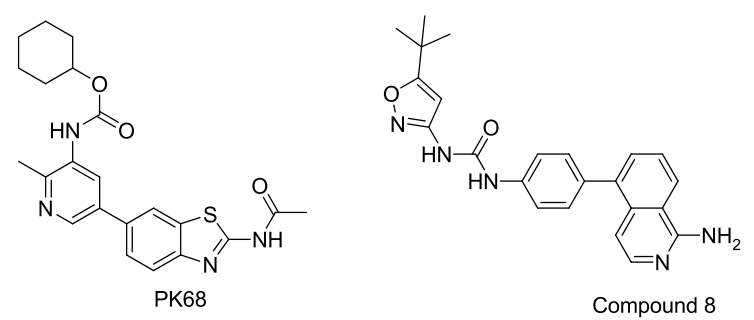

Compound 8 b

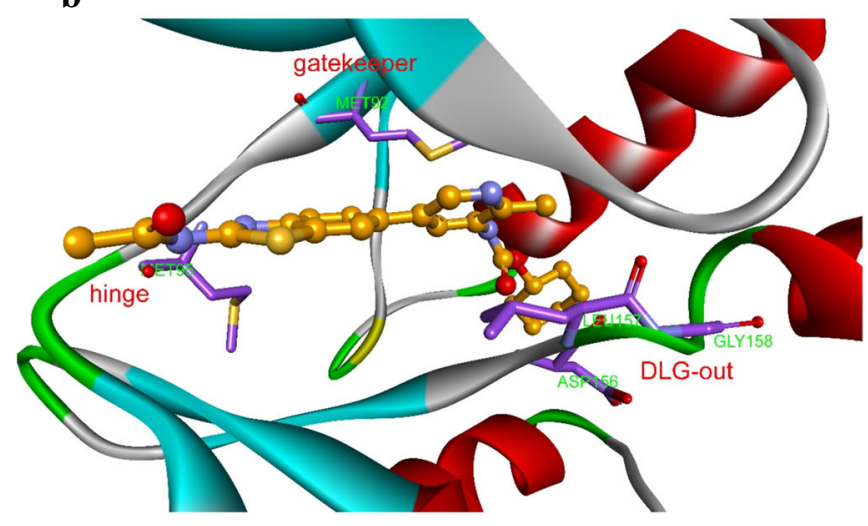

c

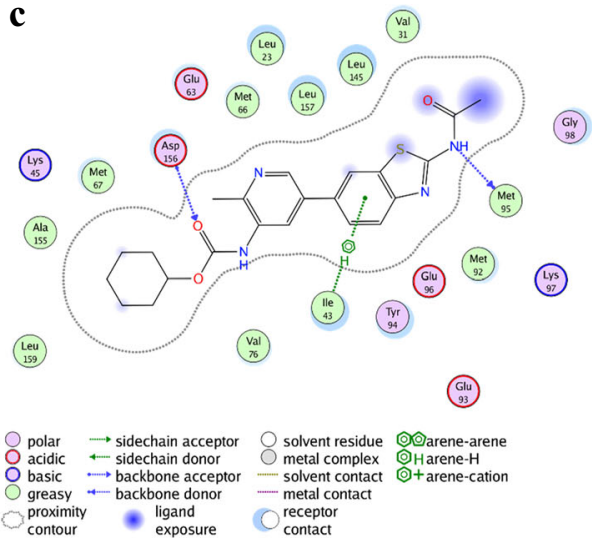

Fig. 5 The molecular docking of PK68 on RIPK1 indicates PK68 as a type II inhibitor of RIP1 kinase. a Chemical structures of PK68 and compound 8 in 4NEU. $\mathbf{b}$ The predicted binding conformation of PK68 derived from Glide docking study. $\mathbf{c}$ Schematic representation of the interaction patterns between PK68 and the key residues in the binding pocket of RIPK1 kinase

$4897 \mathrm{ng} \mathrm{h} / \mathrm{ml}$, leading to an estimated oral bioavailability of $61 \%$ (Fig. 6a, b).

PK68 exhibited an $\mathrm{EC}_{50} \sim 20 \mathrm{nM}$ in the cell-based assay (HT-29 cells treated with TNF $\alpha / S m a c$ mimetic/z-VAD). When dosed orally at $10 \mathrm{mg} / \mathrm{kg}$ in mice, PK68 exhibited a Cmax of $2423 \mathrm{ng} / \mathrm{ml}$, translating to a plasma concentration of $\sim 4000 \mathrm{nM}$. Judging by the PK time curve, the observed plasma levels of PK68 were above its $\mathrm{EC}_{50}$ over a period of $8 \mathrm{~h}$. Based on these results, we hypothesized that the preliminary toxicity of PK68 could be evaluated at a low dose $(5 \mathrm{mg} / \mathrm{kg})$ and a high dose $(25 \mathrm{mg} / \mathrm{kg}$, which should support plasma concentration of PK68 well above its $\mathrm{EC}_{50}$ for $24 \mathrm{~h}$ ). These doses were meant to determine the preliminary toxicity effects of PK68 (Fig. 6c). PK68 was well tolerated at both doses $(5$ and $25 \mathrm{mg} / \mathrm{kg}$, daily oral gavage dosing). All tested animals exhibited normal body weight and behavior, and consumed a normal amount of food as compared with the vehicle group throughout the 14-day observation period (Fig. 6c). We further performed histology of various tissues from mice that had received 14-day treatment of PK68. Tissues including lung, liver, and heart from PK68-treated mice showed normal morphology like the vehicle-treated mice (Fig. 6d). Collectively, these results show that PK68 exhibits favorable pharmacokinetic profiles and no obvious toxicity in mice treated with a 14-day course at a dose of $25 \mathrm{mg} / \mathrm{kg}$.

\section{PK68 ameliorates TNF-induced SIRS}

Necroptosis is involved in a variety of inflammatory disorders such as TNF-induced SIRS ${ }^{11,12}$. We therefore evaluated the therapeutic effect of PK68 in a mouse model of TNF-induced SIRS. C57BL/6 mice were treated with vehicle, PK6, or PK68 for $15 \mathrm{~min}$ prior to intravenous injection of mouse TNF $\alpha$ ( $6 \mu \mathrm{g}$ TNF $\alpha$ per mouse). Treatment with $30 \mathrm{mg} / \mathrm{kg}$ PK6 or $1 \mathrm{mg} / \mathrm{kg}$ PK68 provided effective protection against TNF $\alpha$-induced lethal shock (Fig. 7a). Consistently, treatment of PK68 strongly reduced TNFa-induced temperature loss in mice (Fig. 7b). SIRS is associated with systemic release of proinflammatory cytokines and tissue injuries ${ }^{11}$. In TNFinduced SIRS, PK68 treatment significantly ameliorated the production of proinflammatory cytokines including IL-1 $\beta$ (Fig. 7c). Moreover, TNF-induced damage of the colon was attenuated by the treatment of PK68 (Fig. 7d). Taken together, these results demonstrate that inhibition of RIPK1 by PK68 provides strong protection against TNF-induced SIRS, thus highlighting PK68 as an RIPK1 inhibitor with very promising potential for the development of anti-inflammatory therapeutics.

\section{PK68 displays preventive suppression of tumor metastasis} in the mouse cancer models

Studies have shown that RIPK1 kinase activity is involved in the promotion of tumor metastasis through 
a

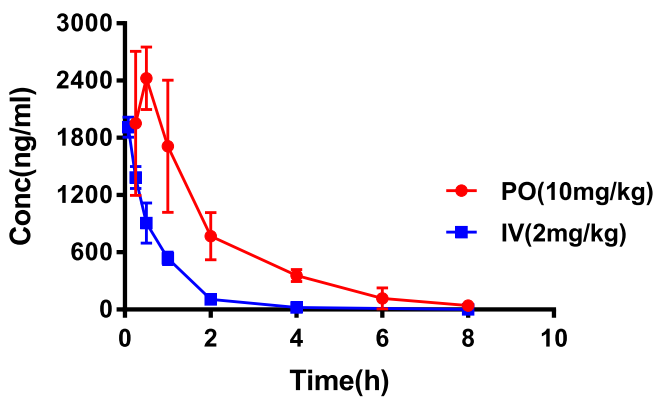

c

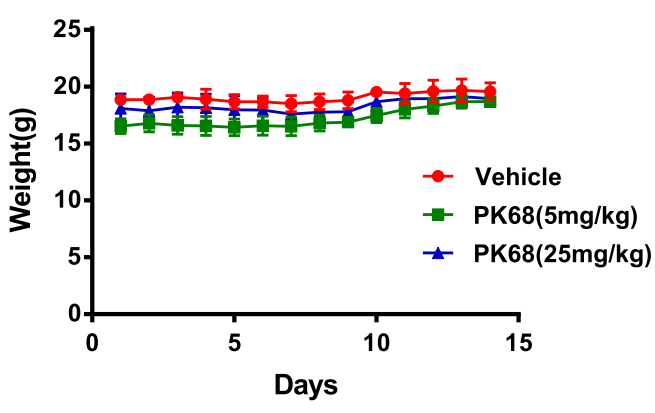

b

\begin{tabular}{c|c|c}
\hline \multicolumn{3}{c}{ PK Parameters } \\
(calculated using the average plasma concentration data) \\
\hline & $\mathrm{PO}($ Gavage $)$ & $\mathrm{IV}$ (Bolus) \\
\hline Tmax $(\mathrm{hr})$ & 0.5 & \\
\hline $\mathrm{Cmax}(\mathrm{ng} / \mathrm{mL})$ & 2423 & 1588 \\
\hline $\mathrm{AUC0}-24\left(\mathrm{ng} / \mathrm{mL}^{\star} \mathrm{hr}\right)$ & 4821 & 1590 \\
\hline $\mathrm{AUCINF}\left(\mathrm{ng} / \mathrm{mL}^{\star} \mathrm{hr}\right)$ & 4897 & 1.0 \\
\hline $\mathrm{t} 1 / 2(\mathrm{hr})$ & 1.3 & 0.8 \\
\hline $\mathrm{MRT}(\mathrm{hr})$ & 1.8 & 1258 \\
\hline $\mathrm{CL}(\mathrm{mL} / \mathrm{hr} / \mathrm{kg})$ & & 21 \\
\hline $\mathrm{CL}(\mathrm{mL} / \mathrm{min} / \mathrm{kg})$ & & 1009 \\
\hline $\mathrm{Vss}(\mathrm{mL} / \mathrm{kg})$ & & 1.0 \\
\hline $\mathrm{Vss}(\mathrm{L} / \mathrm{kg})$ & 61 & \\
\hline $\mathrm{F}(\%)$ & &
\end{tabular}

d

Vehicle
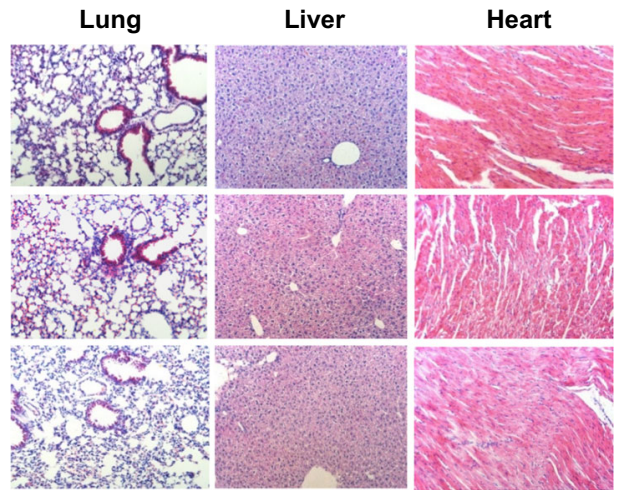

Fig. 6 PK68 exhibits a favorable pharmacokinetic profile and no obvious toxicity in mice. a Plasma concentration of PK68 versus time curves for peros (PO) and intravenous injection (IV). Data represent mean value \pm standard deviation. $\mathbf{b}$ Plasma pharmacokinetic parameters of PO and IV. $\mathbf{c} \mathbf{d}$ C57BL/6 mice $(n=5)$ were treated with the indicated daily oral gavage dosing of PK68 for successive 14 days. Body weight (c) and hematoxylineosin (H\&E) staining (d) of mice were analyzed. Control mice received an equal amount of vehicle. Magnification: $\times 40$. Data represent mean value \pm standard deviation

death receptor 6-dependent necroptosis of endothelial cells $^{22}$ or VEGF-dependent activation of vascular permeability $^{42}$. We thus evaluated the therapeutic effect of PK68 on lung metastasis of mouse melanoma B16-F10 cells in vivo. As shown in Fig. 8a, C57BL/6 mice received tail intravenous injection of B16-F10 cells and then developed lung metastasis. After 2 weeks, the metastasis of B16-F10 cells was measured by histological analysis and assessed as the number of metastasis nodules in the lung. Notably, pre-treatment of PK68 significantly reduced the number of pulmonary metastasis nodules, suggesting an inhibitory effect of PK68 on metastasis of B16-F10 cells to the lungs in mice (Fig. 8a, b). Consistently, PK68-pre-treated mice showed markedly decreased lung metastasis of RFPlabeled Lewis lung carcinoma LL/2 (RFP-LL/2) cells compared to vehicle-treated mice (Fig. 8c, d). Both B16F10 and RFP-LL/2 cells express RIPK1, but they do not have RIPK3 (Supplementary Fig. 22). Two weeks after intravenous injection of RFP-LL/ 2 cells, $\mathrm{RFP}^{+} \mathrm{LL} / 2$ cells were isolated from the tumor tissues by flow cytometer sorting and no signal of phosphorylated RIPK1 was detected in these tumors cells (Supplementary Fig. 22).
Six hours after intravenous injection of RFP-LL/2 cells into C57BL/6 mice, the RFP-LL/2 cells have extravasated through blood vessels into the lung (Supplementary Fig. 23). We found that pre-treatment of PK68 resulted in decreased number of RFP-LL/2 cells in the lung $6 \mathrm{~h}$ after intravenous injection of RFP-LL/2 cells (Supplementary Fig. 23), supporting an inhibitory effect of PK68 on extravasation of tumor cells through blood vessels. Further, we evaluated the effect of PK68 on the tumor cell transmigration across the cultured endothelium. We isolated $\mathrm{CD}_{3} 1^{+}$endothelial cells from the lungs and performed the transendothelial migration assay as previously reported $^{42}$. Addition of PK68 attenuated transmigration of RFP-LL/2 cells through the endothelial cell monolayer (Supplementary Fig. 24), while treatment of PK68 or Nec$1 \mathrm{~s}$ had no obvious influence on the proliferation rate and invasion ability of B16-F10 or RFP-LL/2 cells without the endothelial cell monolayer in vitro (Supplementary Fig. 25). These findings demonstrate that inhibition of RIPK1 by PK68 results in attenuated tumor cell transmigration across the endothelial barrier and preventive suppression of tumor metastasis. 

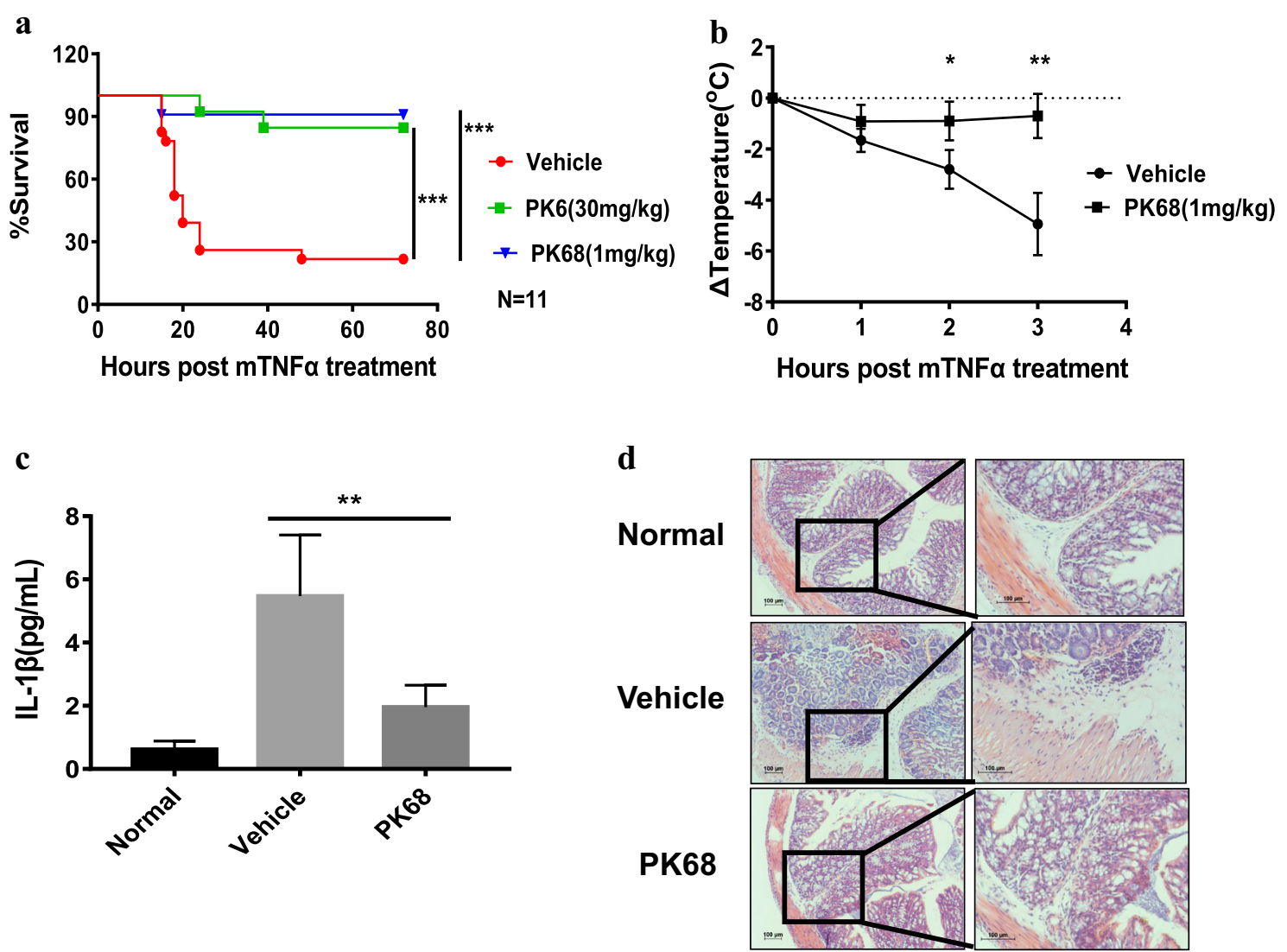

Fig. 7 PK68 ameliorates TNF-induced systemic inflammatory response syndrome. C57BL/6 mice $(n=11)$ were injected with vehicle, PK6 (30 mg/kg), or PK68 (1 mg/kg) via intraperitoneal injection for $15 \mathrm{~min}$, followed by the tail intravenous injection of mouse TNF-a (6 $\mathrm{\mu g}$ per mouse). $\mathbf{a}, \mathbf{b}$ The survival rate $(\mathbf{a})$ and body temperature loss $(\mathbf{b})$ were monitored. $\mathbf{c}$, $\mathbf{d}$ C57BL/6 mice $(n=5)$ were injected with vehicle or PK68 $(1 \mathrm{mg} / \mathrm{kg})$ for $15 \mathrm{~min}$ prior to the injection of mouse TNF- $a$. The mice were sacrificed $4 \mathrm{~h}$ after TNF-a administration, the serum concentration of IL-1 $\beta$ was measured by ELISA kits (c), and histology of the colon tissue was analyzed by H\&E staining and the representative images are shown (d). The serum or colon tissue from C57BL/6 mice was used as the control (Normal). Magnification: $\times 100$ (left) and $\times 200$ (right). Data represent mean value \pm standard deviation. ${ }^{*} P<0.05 .{ }^{*} P<0.01 .{ }^{* *} P<0.001$

\section{Discussion}

Necroptosis is integral to the pathogenesis of conditions including acute and chronic inflammatory disorders, neuronal and renal degeneration, tumor metastasis, and ischemia-reperfusion-induced tissue injury. Therefore, the essential regulators of the necroptosis signaling pathway like RIPK1 are viewed as promising therapeutic targets. In the current study, we discovered that PK6 and its optimized derivatives including PK68 are a class of novel necroptosis inhibitors that can highly selectively suppress RIPK1 kinase activity and potently block necroptotic cell death, both in vitro and in vivo.

RIPK1 belongs to the RIP kinase family comprising the seven members RIPK1-RIPK7. RIPK1 regulates necroptosis via its kinase function, and it also mediates NF- $\mathrm{KB}$ activation as an adaptor protein independently of its kinase activity, ${ }^{5,2}$. NF- $\mathrm{kB}$ signaling plays is essential for the regulation of multiple inflammatory responses, for cell proliferation, and cell survival ${ }^{43}$. Genetic studies have shown that loss of RIPK1 in mice results in lethality after birth, while mice expressing an RIPK1 kinase dead mutant variant are viable and develop normally ${ }^{12,44}$. Thus, inhibition of RIPK1 kinase activity can be viewed as a potentially attractive therapeutic strategy for intervention in necroptosis without the need to alter its function in the NF-kB pathway. We designed around $~ 300$ small molecules as potential kinase inhibitors with novel structures. Among these, PK6 was identified as an inhibitor of necroptosis using a cell-based assay. Structural optimization of PK6 led to the discovery of PK68, which displayed potent cellular efficacy and in vitro inhibition of RIPK1 kinase activity, with an $\mathrm{IC}_{50}$ of $\sim 90 \mathrm{nM}$.

Assessment of the predicted binding mode demonstrated that PK68 bound to the ATP domain with a DLGout configuration, suggesting PK68 as a type II kinase inhibitor. This result is consistent with the notion that PK68 specifically blocks the kinase activity of RIPK1, but does not interfere with other RIP family members 


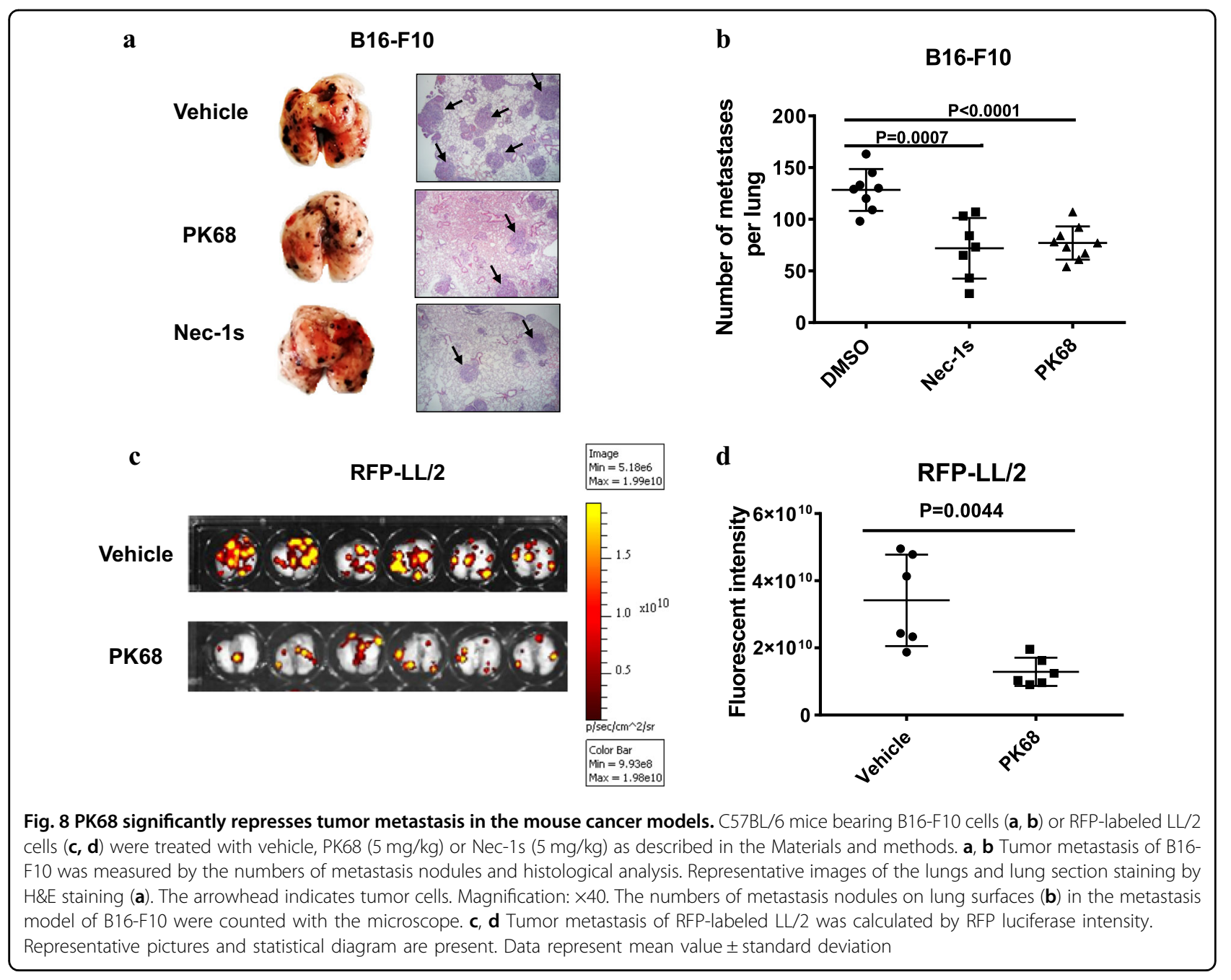

including RIPK2, RIPK3, RIPK4, or RIPK5. Notably, an analysis of 369 human kinases revealed reasonable selectivity of PK68 for RIPK1. As a bona fide RIPK1 kinase inhibitor, PK68 displayed potent cellular efficacy in inhibiting necroptosis cross mice, rat, and humans. This is in contrast to GSK2982772, a type III allosteric RIPK1 inhibitor, which displayed significant differences in activity amongst species. Furthermore, RIPK1 is a pleiotropic protein capable of mediating cell death and NF- $\mathrm{KB}$ signaling. RIPK1 kinase inhibitors, especially those bind to allosteric sites, might induce conformational changes in the protein and therefore impact the scaffolding function of RIPK1 and the ripoptosome, a RIPK1-containing signaling platform for inducing cell death ${ }^{45}$. Supporting this idea, our RIPK1 inhibitors including PK6 and PK68 had no effect on NF- $\kappa B$ activation (Supplementary Fig. 21).

When evaluated in vivo, PK68 displayed a favorable pharmacokinetic profile with an oral bioavailability of $61 \%$ and no detectable toxicity in mice. Furthermore, PK68 is a potent agent against TNF-induced lethal shock, tissue damage, and induction of inflammatory cytokines. Importantly, PK68 significantly repressed tumor metastasis in the mouse cancer models of melanoma and lung carcinoma. These findings strongly highlight the great potential of PK68 for the development of novel antiinflammatory and anti-metastasis therapies. It is also worth noting that the kinase activity of RIPK1 is required to mediate TNF-induced apoptosis in the absence of the activities of cellular inhibitor of apoptosis proteins (cIAPs) ${ }^{46-48}$. In addition, inhibition of RIPK1 kinase activity has been found to attenuate the production of inflammatory cytokines and to improve anti-tumor immunity independently of its role in cell death. Therefore, further understanding of the precise role of RIPK1 kinase activity in relevant diseases models will be critical for the development of valuable therapies using RIPK1 inhibitors. 


\section{Materials and methods Cells and reagents}

HT-29 cells, U937 cells, MKN45 cells, L929 cells, and Panc-1 cells were from ATCC. HT-29-RIPK3 cells, NIH3T3-RIPK3 cells, and mouse MEFs were kindly provided by Dr. Xiaodong Wang (National Institute of Biological Sciences (NIBS), Beijing). HeLa-MLKL (1-190) cell line was a gift from Dr. Zhigao Wang (University of Texas Southwestern Medical Center at Dallas). These cells were cultured in Dulbecco's modified Eagle's medium (Hyclone) supplemented with $10 \%$ fetal bovine serum (Invitrogen) and $2 \mathrm{mM}$ L-glutamine (Invitrogen). Bone marrow-derived macrophages were isolated from the bone marrow of $\sim 7$-week-old mice or $\sim 25$-month-old rats and cultured for 7 days in the medium containing 30\% L929-cell-conditioned medium, 20\% fetal bovine serum (FBS), and 50\% RPMI-1640. L929-cell-conditioned medium containing colony-stimulating factor was collected after growing L929 cells in Dulbecco's modified Eagle's medium (DMEM) plus 10\% FBS for 7-10 days as previously described ${ }^{36}$.

The Smac mimetic compound was kindly provided by Dr. Xiaodong Wang (National Institute of Biological Sciences, Beijing). Necrostatin-1 and z-VAD were purchased from Alexis Biochemicals and Bachem, respectively. LPS and Poly(I:C) were from Sigma and invivoGen, respectively. Recombinant mouse TNF- $\alpha$ was purchased from Genscript. Human recombinant RIPK1, RIPK3, and mouse recombinant RIPK1 were purchased from SignalChem. The cellTiter-Glo Luminescent cell viability assay kit and ADP-Glo kinase assay kit were purchased from Promega.

\section{Antibodies}

The following antibodies were used: anti-RIPK1 monoclonal antibody (BD Bioscience, 610459), antiphospho-RIPK1 monoclonal antibody (Cell Signaling, \#65746), anti-Flag monoclonal antibody (Sigma-Aldrich, F3165), anti-mouse-RIPK3 (Prosci, 2283), anti-phosphoIкB- $\alpha$ monoclonal antibody (Cell Signaling, 9246), and anti- $\beta$-actin monoclonal antibody (Sigma-Aldrich, A2066). The anti-human-RIPK3 polyclonal antibody was generated against full-length human RIPK3 recombination protein.

\section{Cell survival assay}

The cell viability was analyzed by using the CellTiterGlo Luminescent Cell Viability Assay kit following the manufacturer's instructions (Promega). Luminescence was measured with SpectraMax i3x (Molecular Devices).

\section{Western blot analysis}

Cell pellet was collected by centrifugation at $13000 \times g$ for $1 \mathrm{~min}$ and resuspended in lysis buffer $(20 \mathrm{mM}$ Tris-
$\mathrm{HCl}, \mathrm{pH}$ 7.4, $150 \mathrm{~m} 1 \mathrm{M} \mathrm{NaCl}, 10 \%$ glycerol, $1 \%$ Triton X$100,1 \mathrm{mM} \mathrm{Na} \mathrm{VO}_{4}, 25 \mathrm{mM} \quad \beta$-glycerol phosphate, $0.1 \mathrm{mM}$ PMSF, a complete protease inhibitor set (Roche)). The resuspended cell pellet was lysed on ice for $20 \mathrm{~min}$. Then, cell lysates were centrifuged at $13000 \times g$ for $20 \mathrm{~min}$ at $4{ }^{\circ} \mathrm{C}$. The supernatants were collected and subjected to western blot analysis.

\section{Immunofluorescent staining}

HT-29 expressing Flag-RIP3 cells were seeded in a chamber slide and cultured overnight. These cells were pretreated with indicated compounds for $1 \mathrm{~h}$, followed by treatment with TNF- $\alpha$, Smac mimetic, and $\mathrm{z}$-VAD for $12 \mathrm{~h}$. The cells were then washed with phosphate-buffered saline (PBS) followed by fixation in 4\% paraformaldehyde for $10 \mathrm{~min}$. The cells were further washed three times with PBS followed by incubation with $0.25 \%$ Triton X-100 in PBS for $10 \mathrm{~min}$. After that, cells were blocked for $30 \mathrm{~min}$ with 5\% BSA in PBS and stained with anti-flag antibody and secondary antibody successively. Nuclei was stained with DAPI. Images were captured with a Olympus confocal microscope.

\section{In vitro kinase activity assay}

The recombinant RIPK1 or RIPK3 protein was incubated with DMSO or the indicated compound for $15 \mathrm{~min}$ in the assay buffer ( $25 \mathrm{mM}$ HEPES pH 7.2, $20 \mathrm{mM} \mathrm{MgCl}_{2}$, $12.5 \mathrm{mM} \mathrm{MnCl} 2,12.5 \mathrm{mM} \beta$-glycerol phosphate, $5 \mathrm{mM}$ EGTA, $2 \mathrm{mM}$ EDTA, and $2 \mathrm{mM}$ DTT). Then, ATP $(50 \mu \mathrm{M})$ and the substrate MBP $(20 \mu \mathrm{M})$ were added to the reaction at room temperature for $120 \mathrm{~min}$. The luminescence was measured to calculate the kinase activity after the addition of the ADP-Glo Kinase Assay kit following the manufacturer's instructions (Promega).

\section{Kinase selectivity profile}

PK68 was tested at $1 \mu \mathrm{M}$ in duplicate against a panel of 369 human kinases at Reaction Biology Corporation. Results are viewed in the human kinome phylogenetic tree.

\section{Source of animals}

C57BL/6 male mice were purchased from Beijing Vital River Laboratory Animal Technology Co., Ltd. All mice were bred under standard conditions and used at the age of 6-8 weeks with about $20 \mathrm{~g}$ body weight. All animal experiments were approved by the Soochow University Ethics Committee.

\section{TNF-induced SIRS}

PK6 and PK68 were diluted into sterile PBS. C57BL/6 mice were pretreated with vehicle, PK6 $(30 \mathrm{mg} / \mathrm{kg})$, or PK68 $(1 \mathrm{mg} / \mathrm{kg})$ via intraperitoneal injection for around $15 \mathrm{~min}$ and then challenged with mouse TNF- $\alpha$ ( $6 \mu \mathrm{g}$ per 
mouse) via tail intravenous injection. Mice mortality was continuously monitored till $72 \mathrm{~h}$ after TNF- $\alpha$ administration. The serum and colon tissue are collected at $4 \mathrm{~h}$ post TNF- $\alpha$ challenge.

\section{The mouse models of tumor metastasis}

Melanoma B16-F10 cells $\left(0.5 \times 10^{6}\right.$ cells $)$ or RFP-labeled lung carcinoma LL/ 2 cells $\left(0.3 \times 10^{6}\right.$ cells $)$ were injected into C57BL/ 6 mice in a volume of $200 \mu \mathrm{lBS}$ via the tail intravenous injection. Vehicle, PK68 (5 mg/kg), or Nec-1s $(5 \mathrm{mg} / \mathrm{kg})$ was injected intraperitoneally to these mice $30 \mathrm{~min}$ before tumor cells injection, 3 and $6 \mathrm{~h}$ after tumor cells injection. Then, these mice were given the same dose of vehicle, PK68, or Nec-1s every day for 7 days. Fourteen days after injection of tumor cells, mice were sacrificed and lung tissues were collected. The lung metastasis of B16-F10 cells in mice was determined by accounting the number of metastasis nodules with a dissecting microscope (Leica) and histologic analysis. The lung metastasis of LL/2 cells in mice was analyzed by measuring RFP fluorescence intensities with the PerkinElmer IVIS Lumina II. For evaluation of the number of extravasated tumor cells, lung tissues were harvested $6 \mathrm{~h}$ after intravenous injection of RFP-LL/2. Early metastatic RFP-LL/2 cells in the lung were viewed on a fluorescent microscope, and quantified by Image J software. Total RNA of lung tissues was extracted, and the expression level of RFP was analyzed by quantitative real-time PCR.

\section{Transendothelial migration assay}

Primary CD $31^{+}$endothelial cells isolated from lungs by using CD31 beads (Miltenyi Biotec) were used for the transendothelial migration assay as previously described $^{42}$. In brief, CD31 $1^{+}$endothelial cells were cultured for 5-6 days and then seeded on gelatin coated insert in EBM-2 (Lonza). After 2 days, cell culture media was changed with DMEM plus 5\% FBS in the "bottom" wells and with DMEM plus 1\% FBS in the "insert" wells, followed by the treatment of vehicle or PK68 for $2 \mathrm{~h}$ prior to addition of RFP-LL/2 tumor cells. After $20 \mathrm{~h}$, the remaining cells in the "insert" wells were removed. Then fluorescence picture of transmigrated RFP-LL/2 cells were taken at $\times 40$ magnification under the microscope (Nikon), and the intensity of fluorescence was analyzed by Image J software.

\section{Statistical analyses}

Data of cell survival rate are represented as the mean \pm standard deviation of duplicates or triplicates. All experiments were repeated at least three times with similar results. Significance was evaluated using $t$-tests of GraphPad Prism software.

\section{Acknowledgements}

We thank Dr. Xiaodong Wang (NIBS) for providing HT-29-RIPK3 cells, NIH3T3RIPK3 cells, and MEFs; and Dr. Zhigao Wang (University of Texas Southwestern Medical Center at Dallas) for HeLa-MLKL (1-190). We also want to thank

Dr. Zhiyuan Zhang (NIBS) for helpful suggestions on the in vitro kinase assay. This work was supported by the National Natural Science Foundation of China (31671436, 31600133, 81773561, 81473090, and 31830051), the National Basic Research Program of China (2013CB910102), a Project Funded by the Priority Academic Program Development of Jiangsu Higher Education Institutions (PAPD), Natural Science Foundation of Jiangsu Province Grant (BK20160314 and BK20160335), Fok Ying Tung Education Foundation for Young Teachers (151020), China Postdoctoral Science Foundation (2016M601884) and the Nonprofit Central Research Institute Fund of Chinese Academy of Medical Sciences (2017NL31002,2017NL31004).

\section{Author details}

${ }^{1}$ Cyrus Tang Hematology Center and Collaborative Innovation Center of Hematology, State Key Laboratory of Radiation Medicine and Protection, Soochow University, 215123 Suzhou, Jiangsu, China. ${ }^{2}$ Key Laboratory of Stem Cells and Biomedical Materials of Jiangsu Province and Chinese Ministry of Science and Technology, Soochow University, 215123 Suzhou, Jiangsu, China. ${ }^{3}$ Jiangsu Key Laboratory of Neuropsychiatric Diseases and College of Pharmaceutical Sciences, Soochow University, 215123 Suzhou, Jiangsu, China. ${ }^{4}$ Department of Urology, The First Affiliated Hospital of Soochow University, 188 Shizi Rd, 215006 Suzhou, Jiangsu, China. ${ }^{5}$ Center of Systems Medicine, Institute of Basic Medical Sciences, Chinese Academy of Medical Sciences \& Peking Union Medial College, Beijing 100005, China. 'Suzhou Institute of Systems Medicine, 215123 Suzhou, Jiangsu, China. Institute for Cardiovascular Science and Department of Cardiovascular Surgery, The First Affiliated Hospital of Soochow University, Suzhou, Jiangsu, China

\section{Conflict of interest}

S.H. and X.Z. are co-founders, consultants, and shareholders of Accro Bioscience Inc., which supports research in their labs.

\section{Publisher's note}

Springer Nature remains neutral with regard to jurisdictional claims in published maps and institutional affiliations.

Supplementary Information accompanies this paper at (https://doi.org/ 10.1038/s41419-019-1735-6).

Received: 16 January 2019 Accepted: 4 June 2019

Published online: 24 June 2019

\section{References}

1. He, S. \& Wang, X. RIP kinases as modulators of inflammation and immunity. Nat. Immunol. 19, 912-922 (2018).

2. He, S. et al. Receptor interacting protein kinase-3 determines cellular necrotic response to TNF-alpha. Cell 137, 1100-1111 (2009).

3. Cho, Y. S. et al. Phosphorylation-driven assembly of the RIP1-RIP3 complex regulates programmed necrosis and virus-induced inflammation. Cell 137, 1112-1123 (2009).

4. Zhang, D. W. et al. RIP3, an energy metabolism regulator that switches TNFinduced cell death from apoptosis to necrosis. Science 325, 332-336 (2009).

5. Holler, N. et al. Fas triggers an alternative, caspase-8-independent cell death pathway using the kinase RIP as effector molecule. Nat. Immunol. 1, 489-495 (2000).

6. Sun, L. et al. Mixed lineage kinase domain-like protein mediates necrosis signaling downstream of RIP3 kinase. Cell 148, 213-227 (2012).

7. Zhao, J. et al. Mixed lineage kinase domain-like is a key receptor interacting protein 3 downstream component of TNF-induced necrosis. Proc. Natl Acad. Sci. USA 109, 5322-5327 (2012).

8. Cai, Z. et al. Plasma membrane translocation of trimerized MLKL protein is required for TNF-induced necroptosis. Nat. Cell Biol. 16, 55-65 (2014). 
9. Wang, $\mathrm{H}$. et al. Mixed lineage kinase domain-like protein $M L K L$ causes necrotic membrane disruption upon phosphorylation by RIP3. Mol. Cell 54, 133-146 (2014).

10. Chen, $X$. et al. Translocation of mixed lineage kinase domain-like protein to plasma membrane leads to necrotic cell death. Cell Res. 24, 105-121 (2014).

11. Duprez, L. et al. RIP kinase-dependent necrosis drives lethal systemic inflammatory response syndrome. Immunity 35, 908-918 (2011).

12. Berger, S. B. et al. Cutting edge: RIP1 kinase activity is dispensable for normal development but is a key regulator of inflammation in SHARPIN-deficient mice. J. Immunol. 192, 5476-5480 (2014).

13. Onizawa, $M$. et al. The ubiquitin-modifying enzyme A20 restricts ubiquitination of the kinase RIPK3 and protects cells from necroptosis. Nat. Immunol. 16, 618-627 (2015)

14. Newton, $K$. et al. RIPK3 deficiency or catalytically inactive RIPK1 provides greater benefit than MLKL deficiency in mouse models of inflammation and tissue injury. Cell Death Differ. 23, 1565-1576 (2016).

15. Liu, Z. Y. et al. Necrostatin-1 reduces intestinal inflammation and colitisassociated tumorigenesis in mice. Am. J. Cancer Res. 5, 3174-3185 (2015).

16. Yuan, J., Amin, P. \& Ofengeim, D. Necroptosis and RIPK1-mediated neuroinflammation in CNS diseases. Nat. Rev. Neurosci. 20, 19-33 (2019).

17. Degterev, A. et al. Chemical inhibitor of nonapoptotic cell death with therapeutic potential for ischemic brain injury. Nat. Chem. Biol. 1, 112-119 (2005).

18. Linkermann, A. et al. Rip1 (receptor-interacting protein kinase 1) mediates necroptosis and contributes to renal ischemia/reperfusion injury. Kidney Int. $\mathbf{8 1}$ 751-761 (2012).

19. Linkermann, A. et al. Two independent pathways of regulated necrosis mediate ischemia-reperfusion injury. Proc. Natl Acad. Sci. USA 110, 12024-12029 (2013).

20. Luedde, M. et al. RIP3, a kinase promoting necroptotic cell death, mediates adverse remodelling after myocardial infarction. Cardiovasc. Res. 103, 206-216 (2014).

21. Zhang, T. et al. CaMKII is a RIP3 substrate mediating ischemia- and oxidative stress-induced myocardial necroptosis. Nat. Med. 22, 175-182 (2016).

22. Strilic, B. et al. Tumour-cell-induced endothelial cell necroptosis via death receptor 6 promotes metastasis. Nature 536, 215-218 (2016).

23. Lee, T. H., Shank, J., Cusson, N. \& Kelliher, M. A. The kinase activity of Rip1 is not required for tumor necrosis factor-alpha-induced IkappaB kinase or p38 MAP kinase activation or for the ubiquitination of Rip1 by Traf2. J. Biol. Chem. 279, 33185-33191 (2004).

24. Zhou, W. \& Yuan, J. Necroptosis in health and diseases. Semin. Cell Dev. Biol. 35, 14-23 (2014).

25. Conrad, M., Angeli, J. P., Vandenabeele, P. \& Stockwell, B. R. Regulated necrosis: disease relevance and therapeutic opportunities. Nat. Rev. Drug. Discov. 15, 348-366 (2016)

26. Wang, W. et al. RIP1 kinase drives macrophage-mediated adaptive immune tolerance in pancreatic cancer. Cancer Cell 34, 757-774 e757 (2018).

27. Degterev, A. et al. Identification of RIP1 kinase as a specific cellular target of necrostatins. Nat. Chem. Biol. 4, 313-321 (2008).

28. Takahashi, N. et al. Necrostatin-1 analogues: critical issues on the specificity, activity and in vivo use in experimental disease models. Cell Death Dis. 3, e437 (2012).
29. Najjar, M. et al. Structure guided design of potent and selective ponatinibbased hybrid inhibitors for RIPK1. Cell Rep. 10, 1850-1860 (2015).

30. Xie, T. et al. Structural basis of RIP1 inhibition by necrostatins. Structure $\mathbf{2 1}$ 493-499 (2013)

31. Berger, S. B. et al. Characterization of GSK'963: a structurally distinct, potent and selective inhibitor of RIP1 kinase. Cell Death Discov. 1, 15009 (2015).

32. Harris, P. A. et al. Discovery of a first-in-class receptor interacting protein 1 (RIP1) kinase specific clinical candidate (GSK2982772) for the treatment of inflammatory diseaseses. J. Med. Chem. 60, 1247-1261 (2017).

33. Meanwell, N. A. Synopsis of some recent tactical application of bioisosteres in drug design. J. Med. Chem. 54, 2529-2591 (2011).

34. Gehring, P. J., Torkelson, T. R. \& Oyen, F. A comparison of the lethality of chlorinated pyridines and a study of the acute toxicity of 2-chloropyridine. Toxicol. Appl. Pharmacol. 11, 361-371 (1967).

35. Lovering, F., Bikker, J. \& Humblet, C. Escape from flatland: increasing saturation as an approach to improving clinical success. J. Med. Chem. 52, 6752-6756 (2009).

36. He, S., Liang, Y., Shao, F. \& Wang, X. Toll-like receptors activate programmed necrosis in macrophages through a receptor-interacting kinase-3-mediated pathway. Proc Natl Acad Sci USA 108, 20054-20059 (2011).

37. Orozco, S. et al. RIPK1 both positively and negatively regulates RIPK3 oligomerization and necroptosis. Cell Death Differ. 21, 1511-1521 (2014).

38. Liu, S. et al. MLKL forms disulfide bond-dependent amyloid-like polymers to induce necroptosis. Proc. Natl Acad. Sci. USA 114, E7450-E7459 (2017).

39. Harris, P. A. et al. Discovery of small molecule RIP1 kinase inhibitors for the treatment of pathologies associated with necroptosis. ACS Med. Chem. Lett. 4 1238-1243 (2013).

40. Zhao, L. et al. Hydrogen peroxide induces programmed necrosis in rat nucleus pulposus cells through the RIP1/RIP3-PARP-AIF pathway. J. Orthop. Res. 36 1269-1282 (2018)

41. Lu, W. et al. Discovery of potent and novel smoothened antagonists via structure-based virtual screening and biological assays. Eur. J. Med. Chem. 155, 34-48 (2018).

42. Hanggi, K. et al. RIPK1/RIPK3 promotes vascular permeability to allow tumor cell extravasation independent of its necroptotic function. Cell Death Dis. 8, e2588 (2017).

43. Taniguchi, K. \& Karin, M. NF-kappaB, inflammation, immunity and cancer: coming of age. Nat. Rev. Immunol. 18, 309-324 (2018).

44. Kelliher, M. A. et al. The death domain kinase RIP mediates the TNF-induced NF-kappaB signal. Immunity 8, 297-303 (1998).

45. Tenev, T. et al. The Ripoptosome, a signaling platform that assembles in response to genotoxic stress and loss of IAPs. Mol. Cell 43, 432-448 (2011).

46. Petersen, S. L. et al. Autocrine TNFalpha signaling renders human cancer cells susceptible to Smac-mimetic-induced apoptosis. Cancer Cell 12, 445-456 (2007).

47. Vince, J. E. et al. IAP antagonists target CIAP1 to induce TNFalpha-dependent apoptosis. Cell 131, 682-693 (2007).

48. Varfolomeev, E. et al. IAP antagonists induce autoubiquitination of C-IAPS, NFkappaB activation, and TNFalpha-dependent apoptosis. Cell 131, 669-681 (2007). 